\title{
SCREENING OF EGYPTIAN PATEINTS SUFFERING FROM INBORN AMINO ACID METABOLIC DISORDERS
}

\author{
Abd El-Khalek, Heba, S. ${ }^{(1)}$; Zaki, O. K. ${ }^{(1)}$; Mohamed, M. M. ${ }^{(2)}$ \\ and ALGabri, Sammer, $S$.
}

1) Biochemistry Dept. Faculty of Science, Ain Shams University 2) Genetic Research Unit Ain Shams University Hospitals

\begin{abstract}
Diagnosis of aminoacidopathies constitutes a challenge in a developing country with high positive consanguinity rate and no newborn screening programs. The number of diagnosed inborn errors of amino acid metabolism is growing constantly due to the availability of recent analytical technique as tandem mass spectrometry (LC/MS/MS). This study highlights the importance of clinical awareness among physicians in patients presenting with unexplained neurological signs and alarming features that are commonly associated with metabolic diseases.

Our scope is an assessment of overall prevalence rate of amino acid inborn errors metabolism in Genetics Research Unit, Pediatric Hospital, Ain shams University. Results indicate that 851 patients with phenylketonuria (PKU), 109 patients with maple syrup urine disease (MSUD), 15 patients with nonketotic hyperglycinemia (NKH), 14 patients with tyrosinemia, 4 patients with homocystinuria, 4 patients with citruillinimia and 3 patients with arginimia. It is clear that high consanguinity rate among families in different types of diseases that 1 st cousin consanguinity is the highest rate among patients.
\end{abstract}

Keywords: Pku: phenylketonuria, MSUD: maple syrup urine disease, NKH: non ketotic hyperglycinemia, IEM: inborn error of metabolism, HMD: hereditary metabolic disease, NBS: newborn screening.

\section{INTRODUCTION}

Inborn errors of metabolism (IEM) cause hereditary metabolic diseases (HMD) and they result from the lack of activity of one or more specific enzymes or defects in the transportation of proteins. The consequences can 
usually be the accumulation of substances present in small amounts, the deficiency of critical intermediary products, the deficiency of specific final products or furthermore the noxious excess of products of alternative metabolic pathways (Waber, 1990). It seems to be common in the Middle East and North Africa, where high consanguinity rates still prevail due to frequents marriages between close relatives (Teebi, 2006).

They present clinically in a variety of ways, involving virtually any organ or tissue of the body, and accurate diagnosis is important both for treatment and prevention of disease in other family members (Clarke, 2006). There are a few Arab countries in the Middle East and North Africa region that have started a new born screening program (NBS), while others have either a limited hospital-based selective NBS or have just completed pilot studies (AlGazali ;et al., 2006).

Twenty amino acids are involved in metabolism. Each amino acid is further broken down into ammonia, carbon dioxide, and water. Disorders that affect the metabolism of amino acids include phenylketonuria, tyrosinemia, homocystinuria, non ketotic hyperglycinemia and maple syrup urine disease. These disorders are autosomal recessive, and all may be diagnosed by analyzing amino acid concentrations in the body fluids (Hoffmann; et al., 2010).

Tandem mass spectrometry (MS/MS) is an advanced technology that has the ability to identify more than 30 diseases by testing compounds from a single dried blood sample collected from infants during their second to third 
day of life (Mcdonald; et al., 2004). Analysis for identifying each condition is simultaneous and rapid with high specific sensitivity (100\%) and

specificity (100\%). With this technology, many high income countries, such as Italy, Denmark, Canada, Australia، Qatar, and Taiwan have expanded their neonatal screening programme in order to cover more IEM, which in the past consisted only of phenylketonuria (PKU) (Mcdonald ;et al., 2004).

IEM are not rare diseases when we observe their cumulative incidence which is about one in every 5000 live births. Nevertheless, the prevalence of each disease has many variables, especially relating to race. For specific diseases include: 1 in 500 for familial hypercholesterolemia 1 in 12,000 for phenylketonuria (Martins; et al., 1995); 1 in 15,000 for organic acidurias (Seymour et al., 1997); 1 in 60,000 for glycogen storage disease (Martins; et al., 1995); 1 in 45,000 for galactosemia (Seymour et al., 1997) 1 in 100,000 for homocystinuria and 1 in 290,000 for maple syrup urine disease (Seymour; et al., 1997).

In countries where consanguinity rates are high, offspring can inherit the disease from a common ancestor, leading to an increased incidence of inherited disorders. The inbreeding coefficient factor ranges from 0.00004 to 0.0008 .In Canada and from 0.001 to 0.005 in the United States (Nussbum; et al., 2004).

Inborn errors of metabolism (IEM) comprise more than 30 genetic disorders that can lead to several serious long-term complications to neonatal and young children. Without rapid diagnosis and appropriate treatment, these diseases can cause mental retardation (MR), physical disabilities, and even death. Although the incidence of IEM seems to be low and varied among 
different ethnicities, high incidences are found in the North American and European populations with an incidence of 40.00 and 29.51 cases per 100,000 live births respectively (Applegarth; et al., 2000), whereas the incidences of IEM in Asian populations is ranged between 16.08-26.35 in 100,000 live births (Niu; et al., 2010).

\section{SUBJECTS AND METHODS}

This cross sectional study included 1000 clinically diagnosed patients with IEM under treatment including phenylketonuria, tyrosinemia, non ketotic hyperglycinemia, citrullinemia, hyprarginimia, homocystinuria and maple syrup urine disease from the genetic clinic pediatric hospitals, faculty of medicine, Ain Shams university during the period 2005 to 2016.History taking with special emphasis on age of the parents, demographic factors, consanguinity, residence, family history, birth origin, age of start symptoms, age of diagnosis and parents education.

\section{INVESTIGATIONS}

Dry blood test by LC/MS-MS: Blood samples used for LC/MS-MS screening were taken by striking the heels of patients, spotted on Whatman filter paper cards (Scleicher and Schulell 903; Dassel, Germany) and left to dry before screening by tandem mass spectrometry (Triple Quadruple, Waters, Germany) as described in the manufacture guide to measure 9 amino acids (Phenylalanine,Leucine,Isoleucine,Valine,Tyrosine,Methionine,Glycine and Arginine and Citruilline) 
A total number of 1000 clinically diagnosed patients with inborn errors of amino acid metabolism including phenylketonuria, maple syrup urine disease, tyrosinemia and non ketotic hyperglycinemia, homocystinuria, arginimia and citruillinimia were selected from the pediatric hospitals ,Ain shams univesity. All pateints were undergone to many laboratory methods to confirm the clinical diagnosis.

They were divided into 851 patients with phenylketonuria, 109 patients with maple syrup urine disease, 14 patients with tyrosinemia, 15 patients with nonketotic hyperglycinemia, 4 patients with homocystinuria, 3 patients with arginimia and 4 patients with citruillinimia. (table1).

Table (1): Distribution of selected patients with IEM

\begin{tabular}{|c|c|c|}
\hline Classification & Number of cases & Percent \\
\hline \hline Phenylketonuria & 851 & $85.1 \%$ \\
\hline Maple syrup urine disease & 109 & $10.9 \%$ \\
\hline Nonketotic hyperglycinemia & 15 & $1.5 \%$ \\
\hline Tyrosinemia & 14 & $1.4 \%$ \\
\hline Citrullinimia & 4 & $0.4 \%$ \\
\hline Homocystinuria & 4 & $0.4 \%$ \\
\hline Arginimia & 3 & $0.3 \%$ \\
\hline
\end{tabular}

\section{RESULTS AND DISCUSSION}

A) Data of PKU.: It is obvious that number of PKU patients in Upper Egypt (Suhaj, Alfayyum , Asyut, Aljizah,, BaniSuwayf, Qina, Almina, Aswan and Aluqsur) represented $44.2 \%$, while it is unexpectedly high in lower Egypt (Alqahirah ,Alqalyubiyah, Aliskandariyah, Albuhayrah, Ashsharqyah, Alminufyah, Algharbiyah, Kafreashshaykh, Addaqahliyah, Dumyat,Alismailiyah, Bursaid and Assuways) represented 55.8\%. 
Representing consanguinity percentage, it is clear that high consanguinity rate among PKU families (1st cousine consanguinity) and the large number of cases was from Cairo and Sohag.

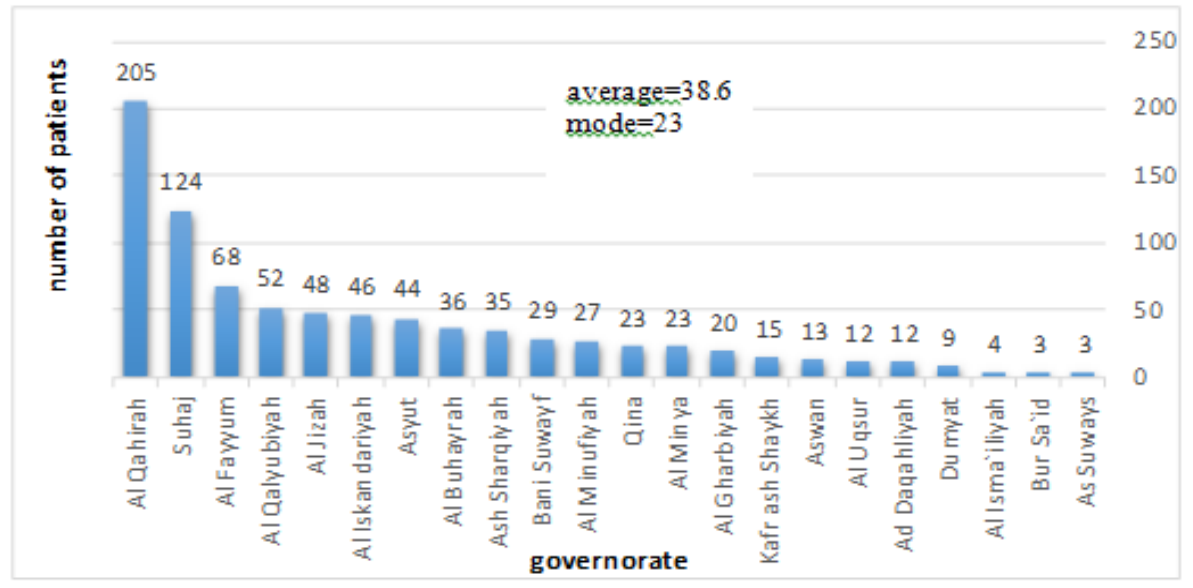

Figure (1): Distribution of patients with PKU in Governorates. The large number of cases was from Cairo (205 patients) and Sohag (124 patients).

B) Data concerning MSUD: It is obvious that number of MSUD patients in Upper Egypt represents $28.5 \%$ while it was again higher in Lower Egypt 71.5\%. Representing consanguinity percentage, it is clear that high consanguinity rate was among MSUD families (1stcousin consanguinity) and the large number of cases was from Cairo. 


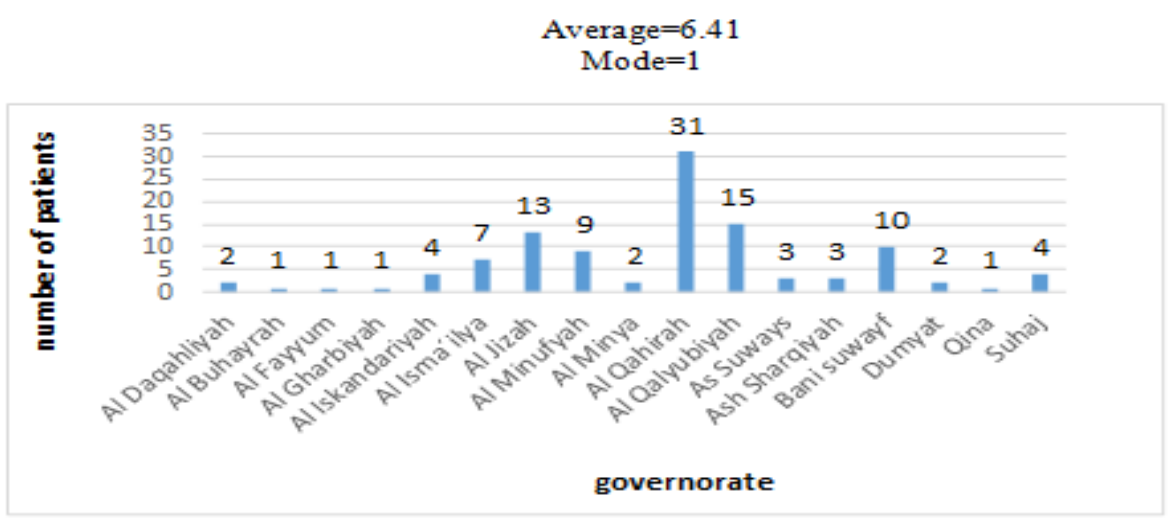

Figure (2): Distribution of patients with MSUD in Governorates. The large number of cases was from Cairo (31 patients).

C) Data concerning a NKH.: It is clear that number of NKH patients is relatively small compare to other two previous IEM diseases which contains 15 patients. Representing consanguinity percentage, it is clear that high consanguinity rate was among $\mathrm{NKH}$ families (1st cousin consanguinity) and the large number of cases was also from Cairo.

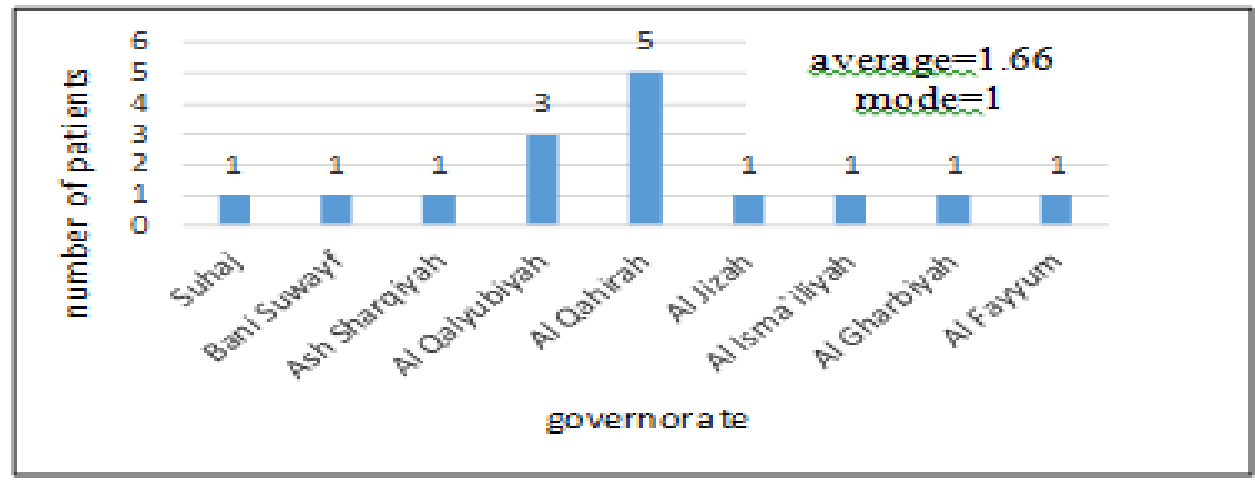

Figure (3): Distribution of patients with NKH in Governorates. The large number of cases was from Cairo (5 patients). 
D) Data concerning a Tyrosinimia. It is obvious that number of Tyrosinimia patients was 14 patients. Concerning consanguinity percentage, it is clear that high consanguinity rate was among Tyrosinimia families and the large number of cases was reported from Cairo (10 patients).

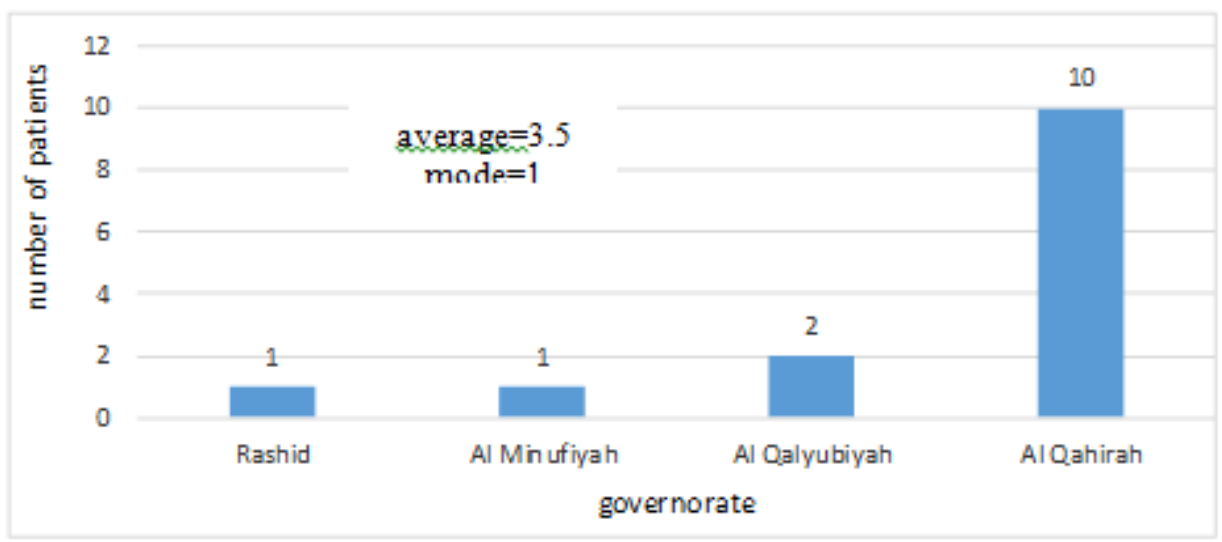

Figure (4): Distribution of patients with Tyrosinimia in Governorates. The large number of cases was from Cairo (10patients)

E) Data concerning a Citrullinimia. Again, it is obvious that number of citruillinimia patients was only 4 patients. Representing consanguinity percentage, it is clearthat high consanguinity rate is among Citruillinimia families and the large number of cases was from Cairo. 


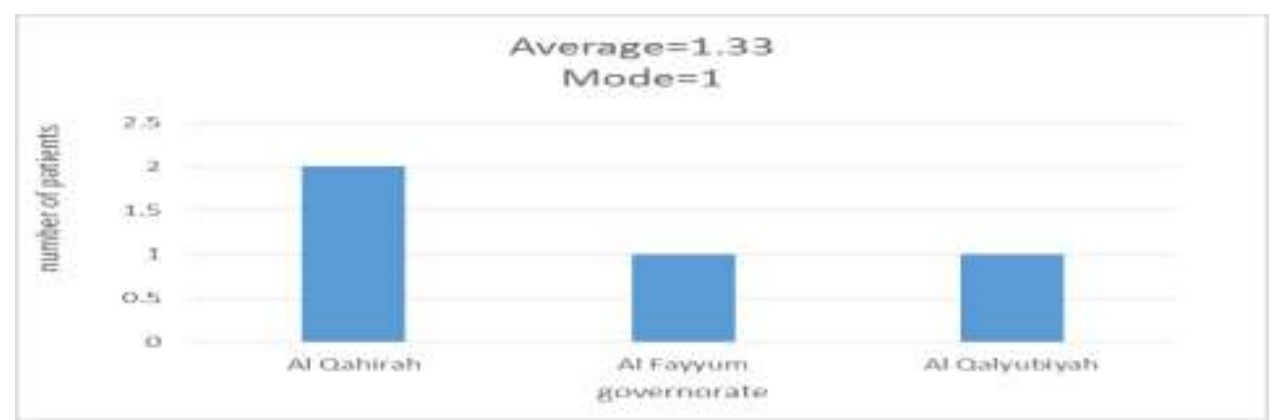

Figure (5): Distribution of patients with citrullinimia in Governorates. The large number of cases was from Cairo (2 patients).

F) Data concerning homocystinuria.: It is obvious that number of homocystinuria patients was 4 patients. Representing consanguinity percentage, it is clear that high consanguinity rate among homocystinuria families and the large number of cases was also from Cairo (2 patients).

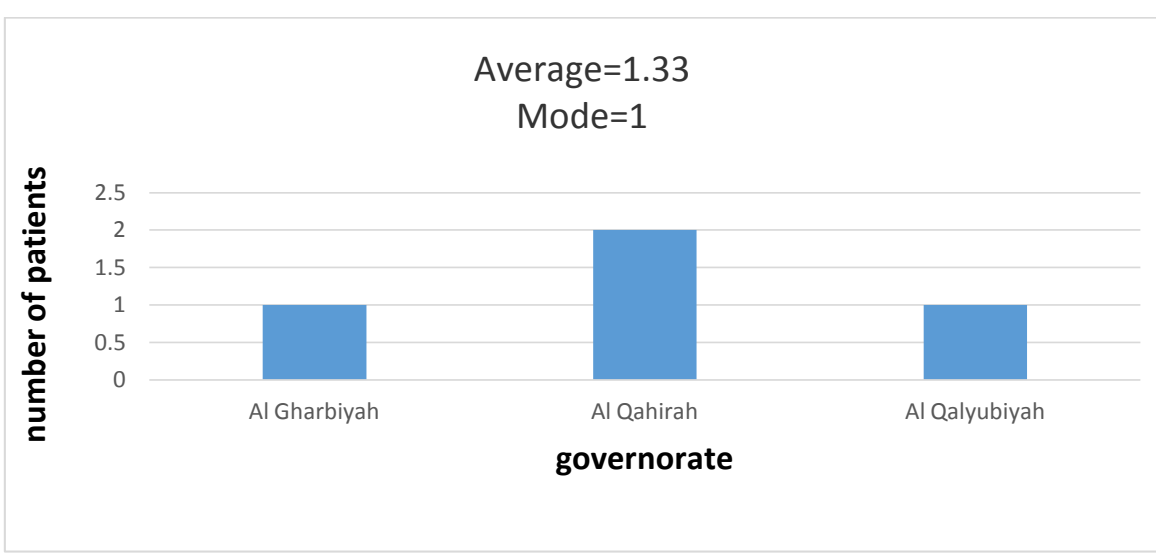

Figure (6): Distribution of patients with Homocystinuria in Governorates. The large number of cases was from Cairo. 
G) Data concerning an Arginimia.: It is obvious that number of arginimia patients was 3 patients. Representing consanguinity percentage, it is clear that high consanguinity rate among Arginimia families and the large number of cases was from cairo (2 patients).

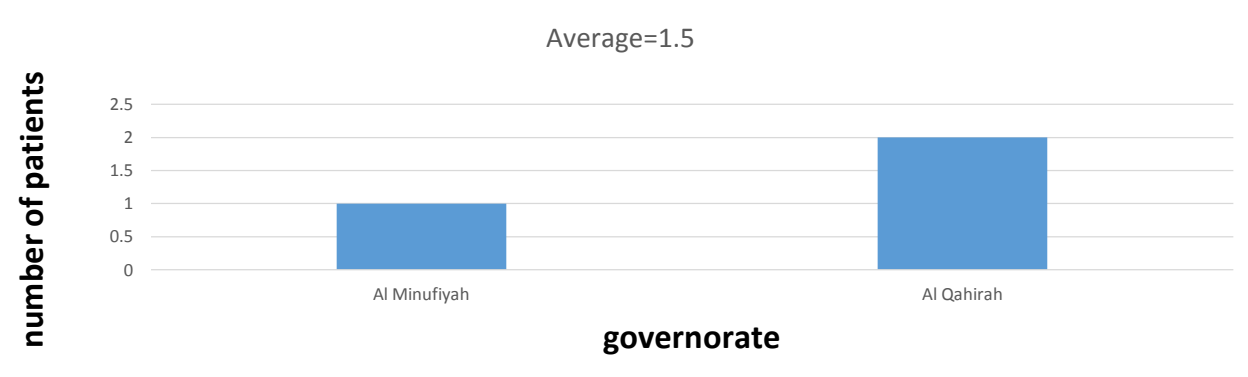

Figure (7): Distribution of patients with Arginimia in Governorates. The large number of cases was from Cairo (2 patients).

This study included patients diagnosed as IEM in amino acid metabolism who were presented to the Genetics Unit during the period from January 2005 to June 2016. It aimed to assess the overall prevalence of these diseases, and to find the relationship between demographic, ecological factors and different types of inborn errors of amino acid metabolic disorders.

In this study, we had 851 patients with PKU families. High level of positive consanguinity was found among PKU families (83.9\%) and first cousin marriage was found (56.2\%) and second cousin marriage (25.2\%). As regard to maple syrup urine disease, 109 MSUD patients from 98 families were included in this study. The diagnosis was confirmed by elevated level of leucine, isoleucine, and valine in blood using LC/ MS/MS. High level of 
consanguinity was found among MSUD families (89.9 \%) and (62.2\%) showed first cousin consanguinity.

In our study, we had 15 patients with non-ketotic hyperglycinaemia $\mathrm{NKH}$ in 15 families. First cousin consanguinity was found in (53.33\%). Sex distribution was $7(46.66 \%)$ males and $8(53.33 \%)$ females. As regard tyrosinemia type 1, we had 14 cases in 11 families. Consanguinity was $(92.85 \%)$ and first cousin consanguinity was (50\%). Moreover, we had three patients with arginimia in three families. First cousin consanguinity was found in (66.66). Sex distribution was 2 (66.66\%) males and 2 (33.33\%) females. As regard homocystinuria, we had 4 cases in 4 families. Consanguinity was (50\%) and first cousin consanguinity was (25\%). In this study, we had 4 patients with Citruillinimia in 4 families. High level of consanguinity was found among citruillinimia families (100\%).

Consanguineous marriages are very common in Egypt (35.3\%) (Shawky et al., 2011) which lead to increase the risk of metabolic disorders. In this study, consanguinity was high $(72 \%)$ and $26.5 \%$ of the families were found to have a positive family history of an IEM or of unexplained death among their families which with other studies done in Oman (Al Riyami et al., 2012), Jordan (Al-Qaqa et al., 2012) and libya (Alobaidy, 2013). These findings are consistent with the recessive autosomal inheritance of IEMs and reflect the significant contribution of consanguinity in Egypt in this particular health problem.

The high rates of IEM diseases can be attributed to several factors including high rate of traditional consanguineous marriages, which increases the frequency of autosomal recessive diseases; large family sizes, which may 
increase the number of affected children in families with autosomal recessive conditions; the shortage of genetic services and inadequate health care prior to and during pregnancy.

The only way for treatment of pku patients is decreasing its level with Phenylalanine-free milk formula with a diet low in protein. Figure (8) illustrate the level of phenylalanine at onset (pretreated) and its level after treatment with previous formula for 3 months of following up in male and female patients.

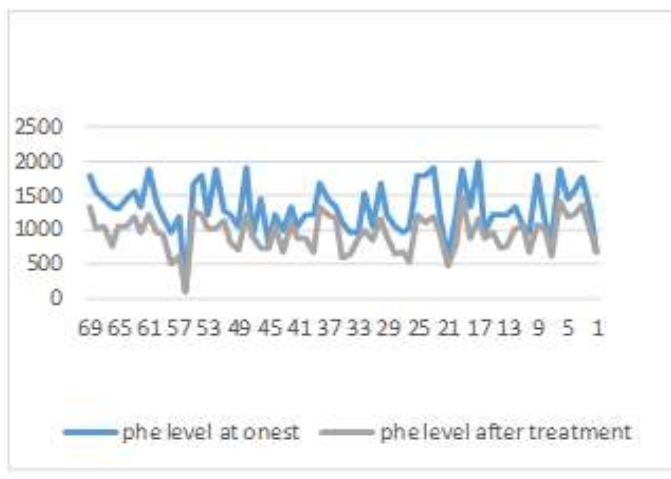

Panal A

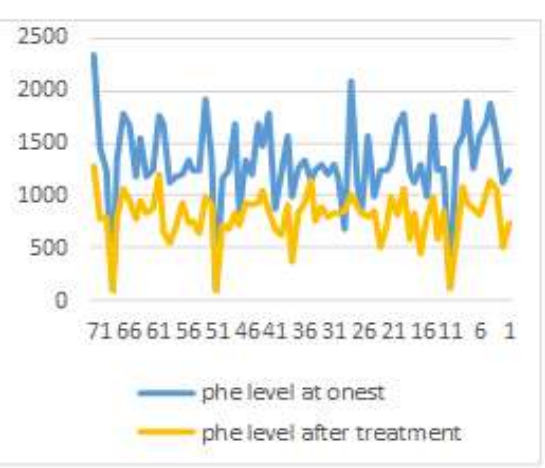

PanalB

Figure (8): Decrease in phenylalanine level after treatment with phe-free milk formula and a diet low in protein in some male patients with PKU.

( Panal A is male PKU pateins of 69 samples and Panal B is Female PKU patients of 71 samples)

Moreover, in order to manage MSUD disease, patients were kept under lifelong clinical management with a diet reduced in BCAAs. They are essential amino acids and important in protein synthesis. 
All patients are treated with BCAA-free milk formula and a diet that contains defined quantities of BCAAs and which is regularly controlled by measuring the levels of the BCAAs in plasma. Figure (9) illustrate the level of leucine/ile at onset (pretreated) and its level after treatment with BCAA free milk formula and a diet low in protein for 3 months following up in male and female MSUD patients.

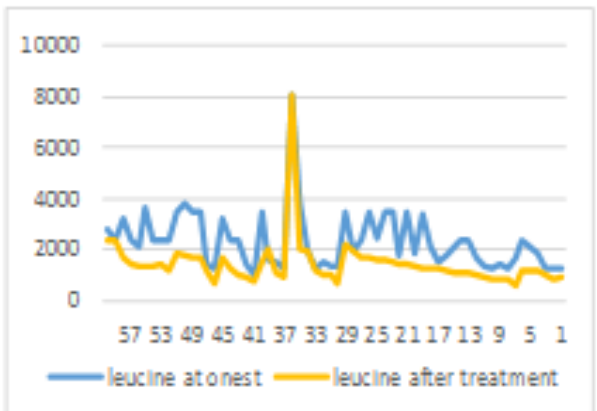

Panal A

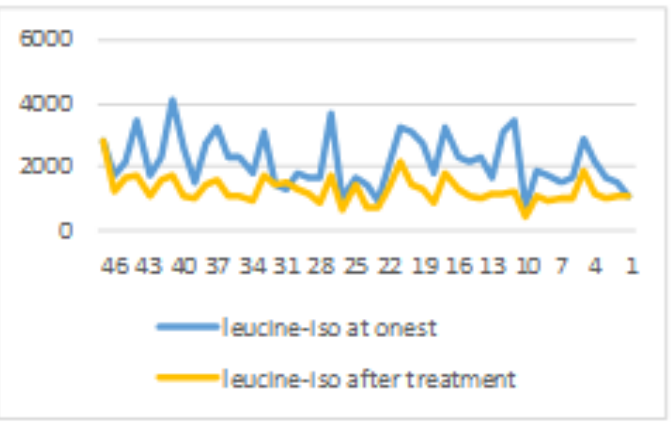

Panel B

Figure (9): Decrease in leucine/ile after treatment with BCAA free milk formula and diet low in protein in male patients with MSUD. (Panal A is male MSUD patients and Panal B is Female MSUD patients).

\section{CONCLUSION}

1- The use of MS/MS has expanded the spectrum of detected IEM disorders by extended metabolic screening.

2- The lack of newborn screening program and specialized healthcare centers in Egypt have contributed to the delay in diagnosis of numbers of patients.

3- Positive consanguinity which was high in our study (84.3\%) has been recognized as the main social factor related to the high prevalence of IEM disorders in Egypt. 
4- Our study provides useful information to the future metabolic newborn screening programs, which should include screening for the most frequent treatable IEM disorders as PKU and MSUD.

\section{REFERENCES}

Al Riyami, S; Al Maney ,M; Joshi S. N. and Bayoumi R.( 2012): " Detection of Inborn Errors of Metabolism using Tandem Mass Spectrometry among High-risk Omani Patients." Oman Medical Journal 27, (6) 482-485.

Al-Gazali, L; Hamamy, H and Al-Arrayad S.( 2006):"Genetic disorders in the Arab world." BMJ 333(7573):831-4.

AlObaidy, H. (2013): "Patterns of inborn errors of metabolism: A 12 year single-center hospital-based study in Libya." Qatar Med J (2):5765.

Al-Qaqa, K; Amayreh, Wand Al-Hawamdeh A.( 2012): " Spectrum of Inborn Errors of Metabolism in Jordan: Five Years Experience at King Hussein Medical Center." Journal of The Royal Medical Services 19(4) 37-41.

DA, Toone JR, Rolland MO, Black SH, Yim DK, Bemis G (2000): "Nonconcordance of CVS and liver glycine cleavage enzyme in three families with non-ketotic hyperglycinaemia (NKH) leading to false negative prenatal diagnoses." Prenat Diagn; 20:367-105.

Clarke, J. (2006): " General principles, In: A clinical guide to inherited metabolic disease, 3rd edition." Cambridge university press pp 127.

Hoffmann, G.F.; Zschocke, J and Nyhan W.L.( 2010): " Inherited Metabolic Diseases." A Clinical Approach (Eds.). Springer-Verlag, Berlin.

Martins, A.M.; Fisberg ,R.M. and Schmidt, B.J. (1995):" Estudio clinico de niños brasilenos con fenilcetonuria, seguimiento a 5 años." Actualidad Nutricional 21(2):66-70. 
Macdonald A, Daly A, Davies P, Asplin D, Hall SK and Rylance G (2004): Protein substitutes for PKU: What's new? J Inherit Metab Dis 27(3): 363-371.

Niu DM, Chien YH, Chiang CC, Ho HC, Hwu WL, Kao SM, Chiang SH, Kao CH, Liu TT, Chiang H, Hsiao KJ (2010): "Nationwide survey of extended newborn screening by tandem mass spectrometry in Taiwan." J Inherit Metab Dis 33:S295-305.

Nussbaum, R.L.; McInnes, R.R. and Williard, H.F (2004):" AUTHOR: Book chapter title missing. In: Thompson, Thompson, editors." Genetics in Medicine. 6th ed. London: Saunders pp. 9-57.

Seymour, C.A.; Thomason, M.J. and Chalmers, R.A (1997): "Newborn screening for inborn errors of metabolism: a systematic review." Health Technol Assess 1(11):1-95.

Shawky,R.M.;El-Awady,Y.M.;Elsayed,S.M. and Hamadan,G.E.( 2011): "Consanguineous matings among Egyptian population." Egypt J Med Hum Genet 12(2):157-63.

Teebi A, El-Shanti H (2006): "Consanguinity: implications for practice." research and policy. Lancet 367:970-71.

Waber, L (1990): "Inborn errors of metabolism." Ped Ann 19(2):105-17 


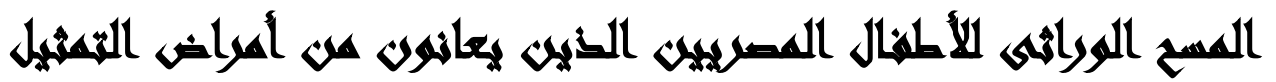

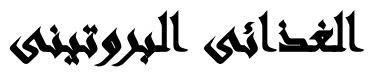

\section{[r]}

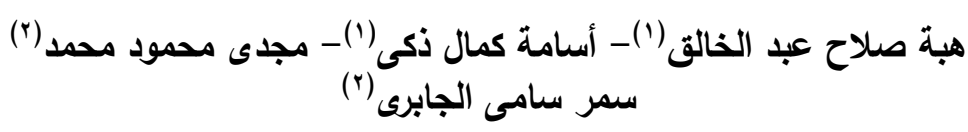

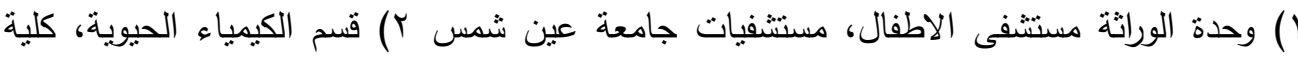

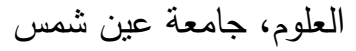

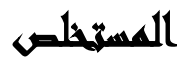

أمراض التمثيل الغذائي هي مجموعة من الامراض التي تتميز عادة بتراكم مواد خطيرة كيميائية

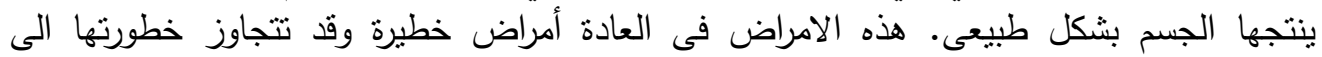

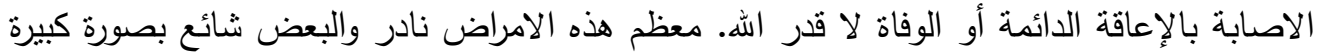

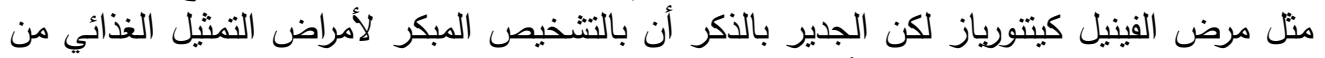

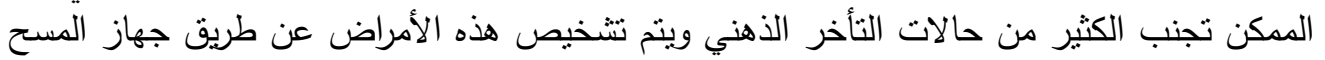

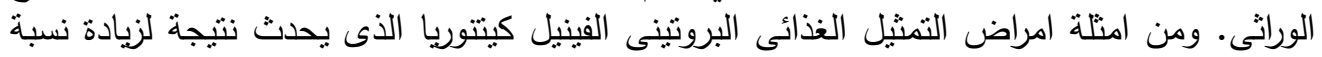

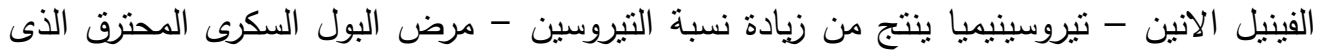

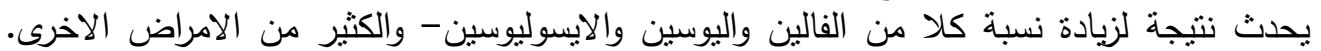
شيوعا.

تهدف الدراسة الى إيجاد علاقة بين نأثير البيئة والموقع الجغرافى على أمراض التمثنل الغذائى التي

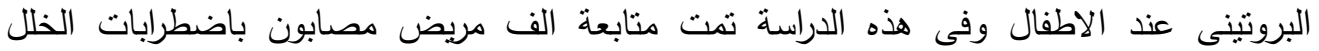

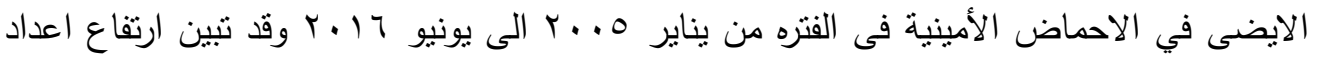

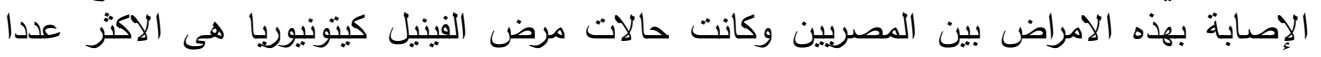

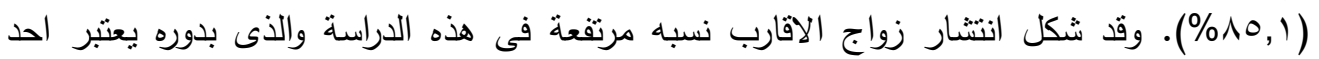

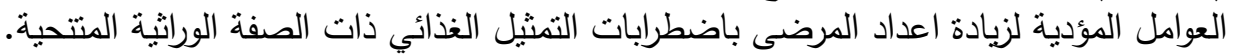

